Wolfgang Neuefeind

\title{
Der Behandlungsvertrag
}

Kommentierung der $\$ \$ 630$ a bis $630 \mathrm{~h} \mathrm{BGB}$ mit Vorbemerkungen zu begleitenden Rechtsthemen 
Wolfgang Neuefeind

Der Behandlungsvertrag 
https://doi.org/10.5771/9783828871946-1

Generiert durch IP '172.22.53.54', am 26.04.2023, 05:14:20.

Das Erstellen und Weitergeben von Kopien dieses PDFs ist nicht zulässig. 
Wolfgang Neuefeind

\section{Der Behandlungsvertrag}

Kommentierung der $\S \S 630$ a bis 630h BGB mit Vorbemerkungen zu begleitenden Rechtsthemen

Tectum Verlag 
Wolfgang Neuefeind

Der Behandlungsvertrag. Kommentierung der $\S \S 630$ a bis 630h BGB mit Vorbemerkungen zu begleitenden Rechtsthemen

(C) Tectum - ein Verlag in der Nomos Verlagsgesellschaft, Baden-Baden 2019

E-Book: 978-3-8288-7194-6

(Dieser Titel ist zugleich als gedrucktes Werk unter der ISBN 978-3-8288-4268-7 im Tectum Verlag erschienen.)

Alle Rechte vorbehalten

Besuchen Sie uns im Internet www.tectum-verlag.de

Bibliografische Informationen der Deutschen Nationalbibliothek Die Deutsche Nationalbibliothek verzeichnet diese Publikation in der Deutschen Nationalbibliografie; detaillierte bibliografische Angaben sind im Internet über http://dnb.d-nb.de abrufbar. 
Rechtevorbehalt: Das Werk ist urheberrechtlich geschützt; die dadurch begründeten Rechte bleiben vorbehalten.

Genderklausel: Grammatisch ist das weibliche Genus durchgängig dem männlichen gleichgestellt - nur aus Vereinfachungsgründen wird die männliche Form gewählt, soweit im Einzelfall nicht anders formuliert ist.

Hervorhebungen: Sämtliche druckgraphischen Hervorhebungen hat der Verfasser gesetzt.

Disclaimer: Verlag und Autor haften für inhaltliche oder drucktechnische Fehler nur beschränkt auf Vorsatz und grobe Fahrlässigkeit. 
https://doi.org/10.5771/9783828871946-1

Generiert durch IP '172.22.53.54', am 26.04.2023, 05:14:20 


\section{Vorwort}

Das Vertragsrecht der medizinischen Behandlung stellt ein Teilgebiet der Gesamtmaterie „Medizinrecht" dar.

Durch das Patientenrechtegesetz vom 20. Februar 2013 hat der Gesetzgeber diesen Bereich mit Wirkung zum 26. Februar 2013 als Untertitel „Behandlungsvertrag" des Titels „Dienstvertrag und ähnliche Verträge" im Bürgerlichen Gesetzbuch eigenständig kodifiziert; dabei sind inhaltlich iSe Kontinuums die wesentlichen Aussagen der bisherigen Rechtsprechung zugrunde gelegt worden.

Die vorliegende Publikation erläutert die Texte der BGB-Normen (je nach Absätzen und Sätzen) anhand der Gesetzesbegründung, der (noch) relevanten älteren und der neueren Rechtsprechung (häufig unter stichwortartiger Mitteilung der Fallcharakteristik) sowie mit Hilfe der einschlägigen Rechtsliteratur und fachbezogener Medienbeiträge.

Das Ziel der Darstellung ist es, dem Nutzer des Textes - als Jurist, als Arzt oder als Patient - einen verdichtet informativen und praktisch verwertbaren Zugriff auf die einzelnen Fragestellungen und Themen zu bieten.

Die Quellenangaben erfolgen teils als parenthetisches Zitieren/Referieren im Fließtext und teils als Anmerkungen/Fußnoten in einem anschließenden Block mit ihrerseits ausführlichen Informationsergänzungen.

Passau, im Herbst 2018

Der Verfasser 
https://doi.org/10.5771/9783828871946-1

Generiert durch IP '172.22.53.54', am 26.04.2023, 05:14:20 


\section{Inhaltsverzeichnis}

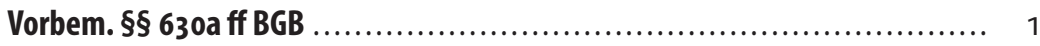

§ 630a BGB (Vertragstypische Pflichten beim Behandlungsvertrag) .......... 26

$\S 630 \mathrm{~b}$ BGB (Anwendbare Vorschriften) ............................... 43

§ 630C BGB (Mitwirkung der Vertragsparteien; Informationspflichten) ....... 48

$\S$ 630d BGB (Einwilligung) ........................................ 54

§ 630e BGB (Aufklärungspflichten) .................................... 62

§ 630 of BGB (Dokumentation der Behandlung) .......................... 72

$\S 630 \mathrm{~g}$ BGB (Einsichtnahme in die Patientenakte) ........................ 77

§ 630h BGB (Beweislast bei der Haftung für Behandlungs- und Aufklärungsfehler) .............................................. 83

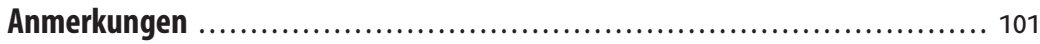

Abkürzungen ...................................................... 155

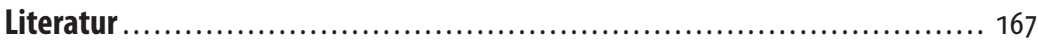

Sachregister........................................................ 173 
https://doi.org/10.5771/9783828871946-1

Generiert durch IP '172.22.53.54', am 26.04.2023, 05:14:20 